cerebellar ectopia. The value of negative contrast studies was emphasized by Wickbom and Hanafee (1963), who analysed the findings of 418 air encephalograms carried out for suspected intracranial space-occupying lesions and found six type 1 and one type 2 anomaly. In Sweden, France, Italy, and Germany air myelography is the method of choice, and iophendylate is rarely used. Jirout (1966) performed air myelography with the patient sitting and the head flexed well forwards.

The classical appearance of the herniated tonsils in cerebellar ectopia is tongue-shaped as described by Liliequist (1960). Unfortunately, occasionally, as in Case 1, the tonsils are not of this shape and are impossible to distinguish from herniated tonsils secondary to raised intracranial pressure. In patients presenting with the disorder in middle life it is imperative to exclude a tumour, and clearly the rest of the posterior fossa and also the cerebral hemisphere must be examined either by air myelography or by arteriography before performing a decompression.

In the non-acute case neuroradiological studies may be performed without risk and at leisure. However, in acute cases investigations may be hazardous. Thus in Case 3 the performance of an air study which failed to outline the fourth ventricle and an iophendylate myelogram, followed shortly afterwards by ventriculography, undoubtedly contributed to the eventual fatal outcome. It is suggested that when sudden deterioration occurs in such a case only one examination should be carried out and posterior fossa decompression performed. The radiologist (J.S.) involved in Case 3, while aware that the fourth ventricle was low, was bent on excluding a lesion pushing it down. This is an extremely common clinical problem. Awareness that the malformation alone may produce such a gross clinical picture is important and may help to prevent similar unfortunate errors.
The importance of adequately examining the upper cervical canal in both the prone and the supine position has been stressed by Baker (1963) and E. G. P. H. du Boulay (personal communication, 1966). Unfortunately, this is by no means routine even with syndromes suggesting upper cervical cord involvement. It is difficult to be dogmatic about whether supine positive contrast myelography is superior to gas myelography. The former is simple and requires no special equipment. The latter is more refined, more time-consuming, and requires special equipment. However, it demonstrates the anatomy so much better that we feel that it will eventually become the method of choice.

We wish to thank Dr. W. Gooddy, Dr. G. Stern, Mr. B. Harries, and $\mathrm{Mr}$. K. Till for permission to publish cases under their care. We are also grateful to Dr. Stern for helpful advice and criticism. One of us (J.S) would like to express his gratitude to Dr. G. H. du Boulay, who first brought home to him the importance of supine myelography in upper cervical syndromes.

\section{REFERENCES}

Appleby, A., Foster, J. B., Hankinson, J., and Hudgson, P. (1968). Brain, 91, 131 .

Arnold, J. (1894). Beitr. path. Anat., 16, 1.

Baker, H. L. (1963). Radiology, 81, 791.

Chiari, H. (1891). Dtsch. med. Wschr., 17, 1172

Chiari, H. (1896). Denkschr. Akad. Wiss., Ẃien, 63, 71.

Cleland, J. (1883). F. Anat., 17, 257.

Davies, H. W. (1967). Brit. F. Radiol., 40, 262.

Garcin, R., and Oeconomos, D. (1953). Les aspects neurologiques des malformations congénitales de la charnière craniorachidienne. Paris. Gardner, W. J., Abdullah, A. F., and McCormack, L. J. (1957). 7. Neurosurg., 14, 591.

Gardner, W. J., and Goodall, R. J. (1950). 7. Neurosurg., 7, 199.

Jirout, J. (1966). Neuroradiologie. Berlin.

Liliequist, B. (1960). Acta Radiol., 53, 17 .

List, C. F. (1941). Arch. Neurol.' Psychiat. (Chic.), 45, 577.

Spillane, J. D., Pallis, C., and Jones, A. M. (1957). Brain, 80, 11 Symonds, C. P., and Meadows, S. P. (1937). Brain, 60,52. Wickbom, I., and Hanafee, W. (1963). Acta radiol. (Diag.), 1, 647.

In view of the present interest in asbestosis it was considered that an attempt should be made to correlate the asbestos count on histological section with the pulmonary radiographic find-

ings, with a view to discovering if there is a level at which evidence of asbestosis becomes discernible on a chest radiograph.

Earlier reports have shown that the incidence of asbestos bodies found in lung smears at routine necropsy has varied from 20 to $47 \%$ (Cauna, Totten, and Gross, 1965 ; Anjilvel and Thurlbeck, 1966 ; Thomson and Graves, 1966 ; Roberts, 1967 ; Ashcroft, 1968), while the incidence in histological section of lung tissue has ranged from 6 to $58 \%$ (Hourihane, 1964 ; Meurman, 1966 ; Gibson, McEwen, Finlayson and Mair, 1968). Elmes and Bell (1968) point out that the inhaled asbestos is distributed comparatively evenly throughout both lungs and have shown that histological section of one segment of lung is representative of pulmonary tissue.

\section{Material and Method}

The report of Gibson et al. (1968) included the findings of 600 consecutive necropsies at the Western Infirmary, Glasgow. Lung was sampled from the base of either lower lobe and histological examination made of a single unstained 30-micron 
paraffin section. The number of asbestos bodies was counted in an area $1.5 \mathrm{~cm}$. square. The incidence of positive counts was $41.5 \%$. Our survey is concerned with the radiological appearances of the first 100 of these cases in which a chest radiograph had been taken within one year of death. Lateral views often disclose abnormalities of the posterior part of the diaphragm and posterior sulcus, but in this retrospective survey lateral radiographs were available only in a proportion of cases, so that only frontal radiographs were used.

The chest radiographs were examined for evidence of asbestosis by each radiologist independently, without knowledge either of the other's findings or of the asbestos count. The findings were recorded on a prepared form listing the recognized features of asbestosis-calcified and non-calcified pleural plaques, pleural fibrosis, interstitial fibrosis, pin-point nodulation, bullae, emphysema, neoplasm, or any other significant abnormality (Shanks and Kerley, 1962 ; Paul and Juhl, 1965 ; Anton, 1968 ; Doig, 1968). All radiographs showing appearances suggestive of asbestosis were subsequently examined by both radiologists together.

The results of the radiological review were then related to the asbestos count

\section{Results}

The asbestos count had been found to be positive in 44 and negative in 56 of the cases. Radiological evidence suggestive of asbestosis was found in 9 of the 44 cases with positive counts and in only one of the group with negative counts (Table I).

\begin{tabular}{|c|c|c|c|c|c|}
\hline \multirow{2}{*}{$\begin{array}{l}\text { Asbestos } \\
\text { Count }\end{array}$} & \multicolumn{2}{|c|}{$\begin{array}{c}\text { Negative } \\
\text { Radiographs }\end{array}$} & \multicolumn{2}{|c|}{$\begin{array}{l}\text { Possible Radiological } \\
\text { Features of Asbestosis }\end{array}$} & \multirow[t]{2}{*}{ Total } \\
\hline & Male & Female & Male & Female & \\
\hline $\begin{array}{l}\text { Tegative } . . \\
\text { ositive } \quad .\end{array}$ & $\begin{array}{l}23 \\
22\end{array}$ & $\begin{array}{l}32 \\
13\end{array}$ & $\stackrel{1}{8}^{*}$ & $\stackrel{0}{1+}$ & $\begin{array}{l}56 \\
44\end{array}$ \\
\hline
\end{tabular}

The group with positive counts was divided according to whether or not there were radiographic features suggestive of asbestosis.

(1) Those with positive radiographic features comprised eight men aged 44 to 79 (average 61) years and one woman aged 55 The asbestos counts for the men and the predominant radiographic features are listed in Table II. For the woman the count was 2 ; in this case both observers had noted a single faint opacity in the periphery of the right upper lobe, and thought that it was probably intrapulmonary, though the possibility of its being a pleural plaque could not be excluded.

TABLE II.-Radiographic Features Associated with Raised Asbestos Count

\begin{tabular}{|c|c|}
\hline $\begin{array}{c}\text { Asbestos } \\
\text { Count }\end{array}$ & Radiographic Features \\
\hline $\begin{array}{l}44 \\
95 \\
98\end{array}$ & $\begin{array}{l}\text { Non-calcified and calcified chest wall plaques } \\
\text { "Shaggy" diaphragm; calcified diaphragmatic plaques } \\
\text { Interstitial fibrosis; "shaggy" diaphragm; non-calcified and calci- } \\
\text { fied chest wall plaques; calcified diaphragmatic plaques }\end{array}$ \\
\hline 110 & $\begin{array}{l}\text { fed chest wall plaques; calcified diaphragmatic plaques } \\
\text { Interstitial fibrosis; " shaggy" heart and diaphragm; non-calcified }\end{array}$ \\
\hline 110 & $\begin{array}{l}\text { and calcified chest wall plaques; calcified diaphragmatic plaques } \\
\text { Emphysema; bullae; interstitial fibrosis; pinpoint nodulation; } \\
\text { "shaggy" heart and diaphragm; calcified chest wall and diaphrag- } \\
\text { maticglagues; bronchial carcinoma }\end{array}$ \\
\hline 136 & " Shaggy" diaphragm; peripheral septal lines; non-calcified chest \\
\hline $\begin{array}{l}200 \\
.205\end{array}$ & $\begin{array}{l}\text { "Shaggy" diaphragm; non-calcified chest wall plaques } \\
\text { Emphysema; pinpoint nodulation; interstitial fibrosis; periphera } \\
\text { septal lines; "shaggy" heart and diaphragm; non-calcified chest } \\
\text { wall plaques; calcified diaphragmatic plaques }\end{array}$ \\
\hline
\end{tabular}

(2) Those with negative radiographs comprised 22 men aged 46 to 85 (average 67) years and 13 females aged 40 to 90 (average 65 years. The count exceeded 10 on only four occasions, the results being $28,33,39$, and 60 .

The group with negative asbestos counts contained 24 men aged 45 to 86 (average 64 ) years and 32 women aged 36 to 79 (average 63) years. Only one case was reported as having radiographic features suggestive of asbestosis. Subsequent study of the necropsy report showed that this was a case of progressive systemic sclerosis.

\section{Discussion}

Recent interest has centred on the fact that asbestos bodies have been discovered at routine necropsies in up to $58 \%$ of cases (Meurman, 1966). In this hospital Gibson et al. (1968) report an incidence of $41.5 \%$. From this series we took the first 100 cases in which a chest radiograph had been taken within one year of death. Of these 10044 had positive asbestos body counts. Review of the radiographs showed evidence of asbestosis in eight. At the original reporting, before this reexamination, the fact that the abnormalities could have been due to asbestosis was appreciated in only one of the eight cases. This is of interest and supports the current view that the incidence of radiographic features of asbestosis is higher than was appreciated.

As one would expect, the higher the asbestos count the greater the likelihood of positive radiographic features. Such changes were present in eight of the nine cases in which the count exceeded 40 . In the remaining case there was no radiographic evidence of pulmonary disease (see Chart).

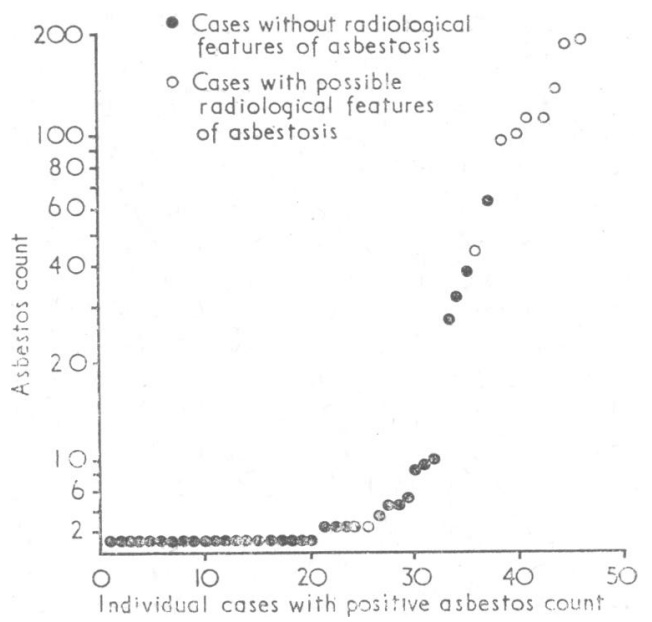

Relation of asbestos count to radiological appearances of asbestosis. The case with possible radiological features of asbestosis and a count of 2 was false positive owing to tuberculosis.

As in other series (Shears and Templeton, 1968 ; Anton, 1968) the commonest finding was the non-calcified pleural plaque on the lateral chest wall, the lesion at that site being more easily seen because it was tangential to the $x$-ray beam. Calcified diaphragmatic pleural plaques were the second most common abnormality detected.

In those eight cases where we consider the radiographic appearances to be due to asbestosis other conditions producing similar changes were excluded by reference to the necropsy reports. In the four cases with counts above 10 , in which no relevant radiological abnormality was detected, necropsy had failed to show macroscopic evidence of asbestosis.

Once case with appearances suggestive of asbestosis and a negative asbestos count was found to have had progressive systemic sclerosis. Diaphragmatic calcification was present in this case in addition to evidence of diffuse interstitial fibrosis. Necropsy showed the interesting feature that the calcification was actually within the diaphragm and not attached to the surface as in asbestosis. The other false positive occurred in a woman with a count of 2 in whom the abnormality proved to be tuberculosis. 
The 12 cases with asbestos body counts of over 10 were all males, and a definite history of industrial asbestos exposure was obtained in 10 cases. The exceptions were an electrician (count 95) and a painter and decorator (count 98). On inquiry by the pathology department it was found that asbestos exposure was a distinct possibility in these cases also.

We are indebted to Dr. A. A. M. Gibson for making the results of his asbestos body count survey freely available to us.

\section{REFERENCES}

Anjilvel, L., and Thurlbeck, W. M. (1966). Canad. med. Ass. 7., 95, 1179.

Anton, H. C. (1968). Brit. F. Radiol., 41, 341.
Ashcroft, T. (1968). Brit. med. F., 1, 614.

Cauna, D., Totten, R. S., and Gross, P. (1965). F. Amer. med. Ass., 192, 371

Doig, A. T. (1968). Hlth Bull. (Edinb.), 26, No. 1, 24.

Elmes, P. C., and Bell, D. (1968). Frequency of Distribution of Asbestos Bodies Within the Lung. Contribution to 11 International Conference on the Biological Effects of Asbestos, Dresden, 1968.

Gibson, A. A. M., McEwen, J., Finlayson, Angela, and Mair, A. (1968). Epidemiology of Mesothelioma in Scotland. Contribution to 11 International Conference on the Biological Effects of Asbestos, Dresden, 1968.

Hourihane, D. O'B. (1964). Thorax, 19, 268.

Meurman, L. (1966). Acta path. microbiol. scand., Suppl. No. 181.

Paul, L. W., and Juhl, J. H. (1965). The Essentials of Roentgen Interpretation, 2nd ed., p. 677. New York.

Roberts, G. H. (1967). \%. clin. Path., 20, 570.

Shanks, S. C. and Kerley, P. J. (1962). A Textbook of X-ray Diagnosis by British Authors, vol. 2 , 3rd ed. p. 616. London.

Shears, G., and Templeton, Ann R. (i968). Brit. med. F., 3, 574.

Thomson, J. G., and Graves, W. M., jun. (1966). Arch. Path., 81, 458.

\title{
Comparison of Preseasonal and Coseasonal Allpyral with Depo-Medrone in Summer Hay-fever
}

\author{
M. A. GANDERTON,* M.B., B.S., D.C.H. ; JONATHAN BROSTOFF, $†$ M.A., B.M., M.R.C.P. ; \\ A. W. FRANKLAND, $\ddagger$ M.A., D.M.
}

Brit. med. F., 1969, 1, 357-358

\begin{abstract}
Summary: Three hundred patients with grass pollen hay-fever, with or without pollen asthma, were given one of three forms of treatment : preseasonal or coseasonal alum-precipitated pyridine extracted grass pollen (Allpyral) or methylprednisolone acetate in slow-release form (Depo-Medrone). Significant improvement was obtained with preseasonal Allpyral and with DepoMedrone, but the degree of improvement obtained with coseasonal Allpyral fell within the limits of placebo response.
\end{abstract}

Nevertheless, it is considered that the definite suppression of the pituitary-adrenal function which results from the use of a long-term steroid is not justified in a benign condition such as hay-fever.

\section{Introduction}

Since the treatment of hay-fever and pollen asthma with multiple injections of aqueous pollen extracts was first described (Noon, 1911 ; Freeman, 1911), other methods which require fewer injections have constantly been sought. Depot injections of allergen in mineral oil emulsion have been used (Loveless, 1947 ; Brown, 1959), but these can cause general as well as severe local reactions (Pearson, 1965), and many are now cautious about using this form of therapy.

An alum-pyridine-precipitated pollen extract was described by Fuchs and Strauss (1959). This seemed as effective as aqueous pollen extracts in the treatment of hay-fever (Harris, 1962 ; Frankland and Noelpp, 1966) and has the advantage of requiring fewer injections. Preseasonal hyposensitization is usually recommended, but if patients require treatment during

\footnotetext{
* Clinical Assistant.

$\dagger$ Registrar.
$\neq$ Director.

Allergy Department the Wright-Fleming Institute of Microbiology, St. Mary's Hospital Medical School, London W.2.

$\$$ Present address: Institute of Clinical Research, Middlesex Hospital Medical School, London W.1.
}

the season and their symptoms are not controlled by antihistamines and antispasmodics, coseasonal hyposensitization or corticosteroids can be prescribed. Hay-fever symptoms have been treated by oral steroids (Evans, 1966) and by injections of methylprednisolone (Brown et al., 1960 ; Arbeiter and Knapp, 1961), but no controlled trials of this form of therapy in summer hay-fever have been performed. It was therefore decided to compare the efficacy of alum-precipitated pyridine extracts of grass pollen, used preseasonally and coseasonally, with depot injections of methylprednisolone acetate given during the season.

\section{Scheme of Trial}

The basis of this trial is similar to others previously described (Frankland, 1965 ; Pearson, 1965) ; only patients with hayfever and asthma whose symptoms were confined to the grass pollen season were included. Each patient kept a daily record of symptoms of any hay-fever or asthma, as well as a record of any untoward symptoms that occurred during treatment. At the end of the season the patient was reassessed, bringing with him the daily record chart. The symptoms of hay-fever and pollen asthma were assessed separately by the patient because any improvement noted in the asthma symptoms did not necessarily run parallel to hay-fever relief. At the end of the season patients were asked to state whether, as a result of treatment, they considered their symptoms were the same, better, or worse compared with previous years. Three groups, consisting of 102,98 , and 100 patients respectively, were treated with either preseasonal or coseasonal alum-precipitated pyridine extracted grass pollen (Allpyral) or injections of $6 \alpha$-methylprednisolone21-acetate in slow-release form (Depo-Medrone). The three groups were comparable with respect to age, sex, age at onse: of symptoms, and the presence of asthma.

Details of treatment are given as follows:

(1) Preseasonal Allpyral.-Subcutaneous injections ranging from 10 protein nitrogen units (p,n.u.) to 2,400 p.n.u. given at weekly intervals for nine weeks during March and April. 